\title{
ARTIGO
}

\section{NA CRECHE, CUIDADOS CORPORAIS, AFETIVIDADE E DIALOGIA}

\author{
DANIELA GUIMARÃES ${ }^{1 *}$ \\ ORCID: https://orcid.org/0000-0002-7358-230X \\ RACHEL ARENARI ${ }^{1 * *}$ \\ ORCID: https://orcid.org/0000-0001-9112-4014
}

RESUMO: Este trabalho tem como objetivo compreender as manifestações afetivas e as possibilidades dialógicas na relação professor-bebê na creche, considerando-as como centrais na ação pedagógica. Com este intuito, foi realizada uma pesquisa de inspiração etnográfica no berçário de uma creche pública numa capital brasileira, onde foram descritas e analisadas práticas pedagógicas na perspectiva da discussão das peculiaridades da docência com bebês. O referencial teórico ancora-se nos estudos de Mikhail Bakhtin e Henri Wallon, de modo especial nos conceitos de dialogia e afetividade. $\mathrm{Na}$ pesquisa, os momentos de cuidado corporal destacaram-se como ocasiões privilegiadas de produção dialógica e manifestação afetiva onde expressões corporais e verbais entrelaçavam-se nos modos dos bebês afetarem os adultos e serem por eles afetados. $\mathrm{O}$ estudo indica que a intencionalidade pedagógica no berçário envolve a atenção para as iniciativas dos bebês, além da qualidade relacional do trabalho cotidiano.

Palavras-chave: Educação Infantil; Creche; Dialogia; Afetividade; Cuidados corporais.

\section{BODY CARE, AFFECTIVITY AND DIALOGY IN NURSERY SCHOOL}

ABSTRACT: This work aims to understand affective manifestations and dialogical possibilities in the teacher-baby relationship in nursery schools, considering them as central in the pedagogical action. With this purpose, an ethnographic inspiration was carried out at nursery of a public nursery school in a Brazilian capital, where pedagogical practices were described and analyzed under the perspective of discussing the peculiarities of teaching babies. The theoretical framework is anchored in the studies of Mikhail Bakhtin and Henri Wallon, especially in the concepts of dialogism

\footnotetext{
${ }^{1}$ Universidade Federal do Rio de Janeiro, Faculdade de Educação,Rio de Janeiro, RJ, Brasil.

"Doutora em Educação PUC-Rio; Professora Adjunta da Faculdade de Educação UFRJ; Coordenadora do grupo de Pesquisa GIDOC (Grupo Infância e Docência na Creche). Email: < danguimaraes@uol.com.br >

"* Mestre em Educação UFRJ. Professora Substituta na Escola de Educação Infantil da UFRJ. Email: < rachelarenari@gmail.com >..
} 
and affectivity. In the research, the body care moments stood out as privileged moments of dialogical production and affective manifestation, where corporal and verbal expressions intertwined the ways the babies affect adults and are affected by them. The study indicates that pedagogical intentionality in nursery school involves attention to the baby's initiatives, besides the relational quality of the daily work.

Keywords: Early Childhood Education; Nursery School; Dialogy; Affectivity; Body care.

\section{PONTOS DE PARTIDA: DOCÊNCIA COM BEBÊS, DIALOGA E AFETIVIDADE}

Este trabalho foi produzido no contexto de uma pesquisa institucional que investiga os sentidos da docência na educação das crianças de 0 a 3 anos. O estudo aqui apresentado tem por objetivo conhecer e compreender como se expressam a afetividade e as manifestações dialógicas nas situações de interação entre adultos e bebês no berçário de uma Escola de Educação Infantil universitária. No processo da pesquisa, os momentos de cuidado corporal destacaramse pela possibilidade de mobilizarem contato, afeto e diálogo.

Em pesquisa recente sobre a construção da docência na creche em plano nacional e, especificamente na realidade catarinense, Rocha e Batista (2015) reafirmam que a perspectiva médicohigienista se destaca na produção de um modelo institucional que compõe a base estruturante da constituição histórica da docência, materializada nas práticas educativas e assistenciais. Ações de tutela sobre os bebês, práticas de guarda e controle reiteram-se no cotidiano de muitas creches brasileiras.

No contraponto da perspectiva sanitarista e higienista, diversos estudos atuais (RAMOS, 2010; CASTRO, 2013; MARTINS FILHO, 2016) focalizam a potência dos bebês nas relações sociais, identificando-os pela capacidade de iniciar contatos, desenvolver interações, sustentar encontros com os pares, relativizando como marcas da atuação do bebê no mundo, a perspectiva do egocentrismo, a ênfase nos aspectos biológicos ou a socialização tardia. Em muitos destes estudos, o papel dos adultos/professores não é o principal foco. No entanto, ressaltam o modo como os adultos estruturam cenários para as ações dos bebês, considerando que os bebês, seus movimentos e os sentidos que evocam oferecem pistas para ações dialógicas por parte dos adultos/professores.

Coutinho (2010), a partir de referenciais da Sociologia da Infância, sublinha as ações sociais dos bebês, buscando seus elementos constituidores. Discute o quanto a estruturação da 
creche, a organização do tempo e do espaço individualizam ou padronizam situações de cuidados físicos (alimentação, banho, sono), obscurecendo os sentidos que os bebês produzem nas relações entre eles. Além disso, pontua o quanto é importante cuidar da resposta adulta às iniciativas das crianças pequenas, indicando perspectiva importante na identidade e na formação de professores. A autora enfatiza como aspectos relevantes a serem observados pelo professor: os movimentos de reprodução/produção das crianças, as relações entre brincadeira/trabalho, o desafio de aprender a "ver as crianças".

Diferentes pesquisas também focalizam as peculiaridades da ação docente com bebês. Schmitt (2014) evidencia alguns conceitos que se mostram importantes na reflexão sobre a docência neste cenário. Por um lado, a multiplicidade simultânea das ações do professor nas interações com as crianças, o que significa que faz parte da docência o olhar, falar e movimentar-se em direções variadas ao mesmo tempo; distribuir a atenção em vários focos. Ao mesmo tempo, a autora destaca a importância de uma Pedagogia de Contexto. Ou seja, o movimento de pensar o planejamento de espaços e tempos como mobilizadores das ações das crianças, na contramão de práticas adultocêntricas, a partir da ação direta do professor.

$\mathrm{Na}$ abordagem destes estudos, os relacionamentos das crianças com os adultos e delas entre si colocam-se como eixos das ações pedagógicas no berçário. Então, compreendemos que referenciais centrados na afetividade e no diálogo, como os que atravessam esta pesquisa, podem contribuir dando consistência à perspectiva do bebê como sujeito relacional e da creche como contexto de aprendizagens sociais.

Nesta trilha, este trabalho tem como interlocutores teóricos principais Mikhail Bakhtin no plano da Filosofia da Linguagem e Henri Wallon na Psicologia histórico-cultural. Apesar de produzirem estudos em campos distintos, os autores destacam a formação subjetiva enlaçada no coletivo, chamando a atenção para como processos afetivos e de construção de sentido por parte dos sujeitos são motores na construção da vida humana e social.

Para Wallon (2005), o ser humano é geneticamente um ser social, "as capacidades biológicas são as condições da vida em sociedade - mas o meio social é a condição do desenvolvimento destas capacidades" (p.14). De outro modo, "o ambiente humano infiltra o meio físico e o substitui em grande parte" (p.140). Isso ocorre desde os primeiros contatos do bebê com o mundo. As emoções, compreendidas como manifestações corporais (choros, expressões viscerais, etc.) afetam o outro que se relaciona com o bebê, produzem 
ressonância e também são significadas no meio humano, tornandose modo de comunicação social. Para o autor, entre as atitudes emocionais daqueles que participam de um mesmo contexto, instituise uma espécie de consonância ou oposição. Então, o contato se estabelece por certo mimetismo ou contraste afetivo, que estabelece uma primeira forma de compreensão mútua. Aos poucos, a mímica se torna linguagem verbal, refreando o arrebatamento das emoções e, ao mesmo tempo, ampliando as manifestações de afetividade. Neste movimento, a fala nomeia o mundo e a si mesmo, trazendo para o bebê novos modos de contato e expressão de afetos.

Para Bakhtin (2011), a dialogia é o caminho pelo qual cada sujeito constitui-se no espaço de tensão entre o eu e o outro. Para o autor, a vida é dialógica; ou seja, "viver significa participar do diálogo: interrogar, ouvir, responder, concordar (...) com os olhos, os lábios, as mãos, a alma, o espírito, todo corpo, os atos" (p. 348). Ou seja, participar da vida social significa produzir enunciados em relação ao outro, mergulhar na corrente discursiva do contexto e colocar-se de modo ativo. Bakhtin (2011) propõe o enunciado como unidade da comunicação humana, afirmando ainda que cada enunciado é um elo na cadeia discursiva, responde a algo que o precedeu e convoca respostas. Assim, o envolvimento dos bebês na corrente dialógica presente em seus contextos permite que eles se coloquem, seja com gestos ou palavras, afirmando-se como sujeitos participantes, ativos e autores das situações compartilhadas. As crianças nascem mergulhadas numa corrente discursiva e dela participam com atos e palavras que anunciam sua autoria em contato e confronto com o entorno.

Neste artigo, para compreender como se expressam a afetividade e a dialogia na creche, foram observadas e registradas práticas pedagógicas em uma turma de berçário de uma Escola de Educação Infantil universitária. Nesta perspectiva, optamos por uma abordagem de viés etnográfico, podendo experimentar as interações, sentidos e aprendizagens que se constituíam no contexto pesquisado. A intenção foi analisar a qualidade das relações na ação docente com os bebês, aproximando-nos do campo da pesquisa e fazendo o necessário distanciamento que nos possibilita a reflexão e compreensão do mesmo.

\section{CAMINHOS DA PESQUISA: A PERSPECTIVA ETNOGRÁFICA}

Sarmento (2011, p. 17) afirma que a etnografia visa "apreender a vida tal como ela é quotidianamente conduzida, simbolizada e interpretada pelos atores sociais nos seus contextos de ação”. Nesta pesquisa, as orientações da etnografia guiaram o trabalho (GEERTZ 1989; VELHO, 2003; DAUSTER, 2003), em especial, a descrição densa 
dos eventos observados; a busca de focalizar o outro, suas organizações próprias, localizando diferenças e especificidades, ultrapassando estereótipos; a identificação de fatos cotidianos que pudessem ser relacionados com temáticas mais amplas na discussão da docência na creche. A convivência intensiva por várias semanas no berçário permitiu capturar sentidos das relações entre adultos e crianças.

No primeiro semestre de 2016 foram realizadas 72 sessões de observação, de 4 horas consecutivas cada uma, três vezes por semana, em diferentes momentos da rotina do berçário: seja no horário da entrada, a partir das $7 \mathrm{~h}$ da manhã, seja no período da tarde, a partir das $12 \mathrm{~h}$. Vale dizer que as situações de alimentação, banho e sono tiveram destaque como momentos privilegiados de manifestação de afeto e diálogo entre adultos e bebês, tanto pela quantidade de tempo empreendida (mais de $50 \%$ do total de $8 \mathrm{~h}$ a $10 \mathrm{~h}$ que as crianças permanecem na instituição), tanto pela importância que os adultos davam a estas situações. A presença do diálogo mobilizado pelo corpo e pela fala e a atenção compartilhada entre adultos e bebês foram especialmente percebidos nos momentos de cuidado corporal, o que mostra a centralidade destes momentos nas práticas pedagógicas na creche.

De fato, o conjunto das situações observadas foram organizadas em três categorias, a partir de suas recorrências: interação entre adultos e crianças no espaço da sala de atividades; interação das crianças entre si também no espaço da sala de atividades e interações nos momentos de cuidados corporais em variados espaços. As situações de cuidado corporal (de modo especial banho, alimentação e sono) ocupavam a maior parte do tempo dos bebês na creche e promoviam diversas oportunidades de troca e manifestação afetiva na relação entre adultos e bebês. Por isso, destacaram-se na produção e reflexões que geraram este trabalho.

$\mathrm{Na}$ pretensão de identificar os modos de atuar dos bebês, acompanhar as suas ações e as relações no contexto educacional, a observação e o registro escrito mostraram-se como caminhos metodológicos pertinentes. Na trilha do que propõe Oliveira (1996), buscávamos olhar, ouvir e escrever com a maior acuidade possível os momentos de relação e contato entre adultos e crianças. $\mathrm{O}$ instrumento metodológico priorizado foi o caderno de campo, onde procuramos documentar de modo denso e detalhado os episódios de interação observados. Como a questão orientadora dizia respeito às manifestações afetivas e à dialogia, buscávamos observar os estilos de comunicação, os modos de interação, anotando os sentidos dos gestos e as palavras proferidas.

Ao longo das observações, buscávamos manter uma atitude 
suficientemente próxima para compreendermos as situações observadas; mas também afastada, tendo em vista produzir a distância necessária para garantir o lugar de exterioridade, fundamental ao pesquisador. Sentávamos no chão, fora do grupo e dos acontecimentos em cena, com olhar interessado e deixandonos interagir com as crianças, quando elas buscavam a interação. Não propúnhamos ou iniciávamos contatos e apontávamos para as crianças o grupo, quando nos procuravam. De acordo com Amorim (2001), o desafio da pesquisa em Ciências Humanas é ser hóspede e anfitrião ao mesmo tempo; ou seja, construir empatia e distância organizadora do que é observado no campo.

A instituição escolhida como campo da pesquisa foi uma Escola de Educação Infantil pública de uma Universidade Federal numa capital da região sudeste do Brasil. A escola atende crianças de 0 a 5 anos e 11 meses de idade. A observação aconteceu no berçário da instituição - chamado de Grupo 1 - composto por bebês a partir dos 4 meses de idade até cerca de 1 ano e meio. A turma era composta por 11 bebês, 5 meninos e 6 meninas, com média 1 ano e meio de idade e um total de 5 professoras (todas mulheres), que se organizam em três turnos diários ( 2 pela manhã, 3 no horário intermediário e 2 na parte da tarde). A escolha dessa instituição como campo da pesquisa aconteceu por conta das condições favoráveis que apresenta do ponto de vista, especialmente, da proporção entre o número de adultos e crianças (de 5 a 6 bebês por adulto) e da proposta pedagógica que focaliza as relações sociais e afetivas como nortes do trabalho cotidiano no berçário. De fato, foi intencional realizar a pesquisa em uma instituição que possui uma proposta pedagógica coerente com as orientações nacionais curriculares para a Educação Infantil, de modo particular as Diretrizes Curriculares Nacionais/2009. O trabalho pedagógico e educacional com bebês é um desafio em muitas regiões de nosso país, tendo em vista a recente incorporação aos sistemas de ensino. Portanto, sublinhar a proposta de uma instituição que realiza este trabalho de modo reflexivo e comprometido é abrir uma janela e ampliar referências para o fortalecimento do trabalho educacional com as crianças de 0 a 3 anos.

Todas as famílias foram consultadas, tendo em vista o consentimento por escrito para a participação dos bebês na pesquisa, manifestando o acordo com o processo de investigação. De todo modo, a presença do pesquisador na turma demandou cuidado e atenção no que diz respeito à observação da receptividade dos bebês e da disposição para a interação. Apesar do consentimento escrito de todos e todas, a publicação do trabalho gera exposição de experiências. Sendo assim, 
outro cuidado ético relevante foi a alteração dos nomes das crianças e das professoras, tendo em vista preservar a identidade delas

No próximo item, descrevemos peculiaridades das observações, especialmente as relações entre professoras e bebês nos momentos dos cuidados corporais, analisando-as a partir da interlocução com os autores citados e com os estudos do campo da Educação Infantil.

É importante destacar que vários trabalhos focalizam o cuidado como categoria pedagógica central neste contexto, discutindo-o em diversas dimensões. Tiriba (2005) sublinha que o aligeiramento do cuidado, percebido como algo menor no cotidiano, relaciona-se com o desprestígio que situações que se aproximam das ações domésticas costumam ter no dia a dia da Educação Infantil, o que nos alerta para a demanda de compreender o cuidado numa perspectiva profissional. Guimarães (2011) discute o cuidado como atenção, numa dimensão que extrapola os cuidados corporais, compreendendo-o como modo de relação dos adultos com as crianças que envolve responsividade e diálogo. Catarsi \& Freschi (2013), no âmbito da experiência italiana, afirmam que cuidar no campo educacional, no contraponto da guarda e da vigília, significa acompanhar o outro no seu percurso de desenvolvimento com atenção e interesse, valorizando o significado formativo da relação. Estes autores destacam que a ritualização, a repetição e o significado emocional dos cuidados físicos/corpóreos conferem a esses momentos da rotina uma centralidade no dia a dia da Educação Infantil. Além disso, para eles, o cuidado relacionase à atenção ao que é singular, de cada criança; mas, ao mesmo tempo, à construção de um clima de grupo, ao planejamento do contexto espaço-temporal, à construção de relações significativas e encorajantes, através das quais o adulto contribui para a construção do bem-estar das crianças. Tais perspectivas reiteraram-se nas análises do campo da pesquisa que apresentaremos em seguida.

\section{O CAMPO DA PESQUISA: RELAC̣̃̃ES DIALÓGICAS, AFETIVIDADE E CUIDADOS CORPORAIS}

O trabalho de Lessa (2011) indica que a alimentação é eixo norteador das rotinas na Educação Infantil. Muitas vezes, as refeições são marcadores de tempo para outras ações. O desafio é pensá-las em sua qualidade pedagógica.

No contexto da creche pesquisada, no final de uma manhã, percebemos que algumas crianças pareciam um pouco inquietas. Uma das professoras explica que naquele horário elas já estavam um pouco aborrecidas porque chegava a hora do almoço e já deveriam 
estar com fome. Ana, Marina e José percebendo a chegada do almoço vão andando em direção à mesa e puxando as cadeiras para se sentar. Pouco tempo depois chega o almoço.

Ana fala: - Papa! Papa!

A professora responde: - É Ana. O papa já vai chegar.

Ana continua: - Papa! Papa!

Algumas crianças já estavam com a Ana, sentando à mesa para esperar o almoço.

Uma funcionária da cozinha chega ao portão pequeno que separa a antessala da sala trazendo uma bandeja com as refeições das crianças e das professoras. Os pratos já chegam prontos da cozinha e as crianças vão para as mesas. [...] As professoras se sentam junto às crianças, ao lado delas na mesma mesa e almoçam ali também. Na medida em que vão comendo vão também conversando, auxiliando aqueles que ainda não conseguem comer sozinhos.

(Caderno de campo, 18/02/16)

O momento da refeição é vivido como um espaço e tempo de partilha de experiências e respeito ao ritmo dos bebês. Há, no desenrolar do almoço, um clima de contato emocional, troca de olhares e sensação de saciedade que contamina o ambiente. Posturas, olhares e gestos mostram imitação, experiências de aprendizagem e de nutrição biológica e afetiva. A atenção é compartilhada, os adultos afetam as crianças porque comem, partilham a experiência do almoço e não só supervisionam ou observam.

A partir do referencial walloniano, afirmamos que mímica, repetição de gestos e linguagem comunicativa entrelaçam-se. Ao mesmo tempo, os enunciados adultos marcam a cena pelo mergulho das crianças na linguagem verbal. Tal como sugere Wallon (2005), percebemos a constituição de certo participacionismo mútuo, ou seja, uma forma de compreensão, consonância e acordo entre as atitudes emocionais dos sujeitos que se encontram num mesmo campo de percepção e ação.

Percebemos também qualidade dialógica no plano de ingresso na linguagem verbal. Já no início do relato, pode-se perceber como a fala da Ana é acolhida pela professora que retoma e estende o enunciado da criança. A professora dialoga com o bebê, recebe a sua fala, devolve com uma elaboração mais complexa e possibilita que Ana continue a repetir a palavra em uma experiência repleta de sentido. A postura ativa da professora demonstra uma escuta atenta e responsiva que fortalece o significado da fala do bebê, ampliando a enunciação. A palavra "papa" proferida por Ana não é uma "palavra isolada", mas engaja-se nos elos da cadeia discursiva que compõem as relações na creche, responde a algo e direciona-se ao outro.

Ao compreender a língua como um signo ideológico, Bakhtin 
afirma que ela não é "adquirida", como algo objetificado exterior aos sujeitos; mas que nela os sujeitos se constituem como pertencentes à cultura.

Na verdade, a língua não se transmite; ela dura e perdura sob a forma de um processo evolutivo contínuo. Os indivíduos não recebem a língua pronta para ser usada; eles penetram na corrente da comunicação verbal; ou melhor, somente quando mergulham nessa corrente é que sua consciência desperta e começa a operar. [...] Os sujeitos não adquirem sua língua materna; é nela e por meio dela que ocorre o primeiro despertar da consciência (BAKHTIN/VOLOSHÍNOV, 2014, p.111)

Bakhtin (2014) aponta que o processo da fala faz parte de um movimento ininterrupto (dialógico) que não tem começo nem fim. De acordo com o autor, "a enunciação realizada é como uma ilha emergindo de um oceano sem limites, o discurso interior" (Idem, p.129), inserida e delimitada por determinada situação e pelas muitas vozes que constituem o sujeito. Cabe aqui olhar também para a fala da criança, percebendo que ela surge em uma dinâmica de continuidade, evocando situações anteriores e provocando ressonância nas produções posteriores, conectada no coletivo.

Nesta perspectiva, a qualidade ritualística da rotina é fundamental, pois estabelece um continente a partir do qual as crianças experimentam antigas e novas cenas, expondo-se de forma mais segura a cada repetição de situação, o que ocorre na cena de almoço narrada acima.

Nesta creche, permite-se que as crianças comam sozinhas, alimentando-se por sua própria ação, com uma intervenção atenta pautada no olhar dos adultos. À medida que recebem as colheres em suas mãos, as crianças começam a mexer com elas na comida que está no prato. A maioria já coloca o alimento na colher, levando-a até a boca. Há um cuidado com o que as professoras podem fazer por e para os bebês, além do que fazem com os bebês, bem como com o que as crianças já podem fazer por si mesmas.

Ao permanecerem sentadas à mesa junto às crianças, as professoras também as desafiam no ato de comer com suas próprias atitudes e com suas falas: "isso, Enzo, comendo tudo" ou "está uma delícia o papá, não é, Heitor"; incentivam as crianças a pegarem a colher quando algumas usam as mãos para pegar e levar o alimento à boca, e auxiliam aos que ainda precisam de ajuda na alimentação. Estabelecese uma dinâmica de parceria e confiança que oferece aos pequenos a oportunidade de irem conquistando mais autonomia e segurança. A fetam as crianças com o olhar, com a repetição de gestos, com as palavras.

Algumas crianças intercalam o transporte do alimento do prato à boca com a colher e com a mão. Alguns seguram a colher com uma mão e colocam a comida sobre ela com a outra mão, outros 
vão pegando a comida com a mão e levando à boca. As professoras emitem enunciados positivos, elogiando o sabor do alimento e impulsionando o uso da colher. Fazem mediação entre a criança e o instrumento, promovendo uma aprendizagem cultural.

Enzo estava comendo com a mão. Pegava uns grãozinhos de feijão, depois o purê, a beterraba e ia comendo, espalhando um pouco a comida sobre a mesa. A professora fala para ele em tom compreensivo: - "Enzo, come com a colher. Olha a colher aí no seu prato. Come com ela". Ele pega mais um pouquinho de comida com a mão e depois pega a colher e começa a comer com ela. Às vezes, ainda usa a ajuda da mão para encher a colher, mas segue comendo.

(Caderno de campo, 23/02/16)

A imitação pelas crianças de gestos, ações, entonações, e demais comportamentos daqueles com quem convivem vão impregnando o corpo delas, de modo que são pouco a pouco apropriados. Nesse movimento, os sentidos e simbolismos seguem sendo partilhados e significados pelos sujeitos no coletivo. Os adultos ocupam um lugar de referência ou ponte para a construção de novas formas de atuação por parte da própria criança, que vive o coletivo como engrandecimento de suas possibilidades.

Os movimentos - silenciosos, mas expressivos - dos bebês também são considerados durante o almoço, indicando que as professoras estão atentas e comprometidas com as possibilidades afetivas dos pequenos.

Em determinado instante uma estagiária que estava ao lado da Marina sai para ajudar outro bebê que não estava comendo na outra mesa.

Marina fica olhando para a estagiária que saiu do seu lado e para de comer.

A professora fala: - "Marina, a (diz o nome da estagiária) vai ajudar a Andrea agora, tá?! Porque ela não está conseguindo comer sozinha, mas nós estamos aqui vendo que você está comendo tudo".

Imediatamente, a Marina se volta para o seu prato e continua a comer. José termina o seu prato e pega com a mão a comida da Ana no prato dela. A professora intervém dizendo: - "José, você já comeu a sua comida e essa é a comida da Ana. Deixa ela terminar de comer".

Ele olha para a professora e para de pegar a comida da colega. Sai andando e vai pegar um dos brinquedos que estavam disponíveis em um canto da sala.

(Caderno de campo, 18/02/16)

Existe no processo do almoço uma ação pedagógica que favorece a segurança e a autonomia dos bebês, aparecendo desde as falas, gestos, olhares e toques, assim como se mostra nos detalhes do preparo do espaço e do alimento. As professoras colocam palavras nas expressões gestuais das crianças que ainda não falam, mas estão 
mergulhadas na linguagem oral e em uma perspectiva dialógica.

Quando chega a sobremesa, quem já acabou de comer vai ganhando um pedaço da fruta e comendo. A sobremesa do dia era melancia e vinha cortada em pequenos bastões.

As professoras iam oferecendo a cada criança a fruta: "Quer melancia Clara? Quer Isabela? Você já comeu melancia? Está docinha".

(Caderno de campo, 18/04/16)

A organização do lanche e a forma de servir o alimento emergem como elementos importantes no planejamento do trabalho cotidiano. Oferecer uma fruta cortada em um formato que permite às crianças segurá-la, sentindo a sua textura, a temperatura, olhando suas cores, saboreando-a e comendo independentemente da ajuda do adulto, significa considerar os bebês enquanto sujeitos na relação educativa. Dessa forma, vemos o intuito de criar oportunidades de aprender, experimentar, marcando a intencionalidade pedagógica.

Barbosa (2010) propõe que na creche o que se define como pedagógico não é vivido apenas através de propostas de atividades dirigidas, mas principalmente na imersão em experiências com pessoas e objetos, constituindo uma história, uma vida coletiva significativa. Por isso, momentos como banho, alimentação e sono não só cuidam do corpo, mas também nutrem as relações e as possibilidades de bem-estar das crianças. Ao mesmo tempo, a organização de contextos diversificados e que respeitem tanto as necessidades como as potencialidades das crianças compõem a docência na creche.

Neste caminho, Schmitt (2014) afirma a urgência de uma docência mais complexa e alargada na educação das crianças de 0 a 3 anos, isto é,

[...] uma ação docente implicada não apenas com aquilo que a professora faz com as crianças pequenas, seja individualmente ou em grupo, mas concomitantemente ligada com uma organização de tempo e espaço que acolhe, fomenta, sustenta, apoia as ações e interações delas consigo mesmas, entre pares e com a cultura. (SCHMITT, 2014, p. 52)

Num outro prisma, na instituição em pauta, o banho dos bebês acontecia logo após o fim do almoço. Conforme terminavam a refeição, algumas crianças já se movimentavam nas cadeiras tentando sair e as professoras mexiam nas cadeiras de modo que elas pudessem sair sozinhas. Alguns olhavam para as professoras, outros também estendiam o braço como quem diz com o corpo que deseja sair dali. A resposta das professoras vinha como quem dialoga com o corpo e com a vOz, num movimento responsivo composto por gestos e palavras.

De acordo com Pino (2005), a fala é um evento social, resultado 
da interação verbal de um locutor e de um interlocutor e, neste caso, alguns bebês já falavam algumas palavras ou repetiam palavras ditas pelas professoras. O Eduardo dizia: - "Saí, saí, saî" ... E a professora perguntava: - "Você quer sair Eduardo?", fazendo um movimento de ajudá-lo na sua saída da mesa. Perguntavam: - "Você quer sair Dante?", já dando a mão para que ele pudesse se levantar e sair.

Em outro momento, enquanto as professoras davam o banho em dois bebês, Eduardo falava: - "Bam, bam, bam". As professoras entendem que o ele fala é "banho", referindo-se ao que está acontecendo ali, e de alguma forma, enunciando que deseja também tomar banho. Há um sentido que é definido na relação com o outro, neste caso a professora. A fala de Eduardo e o contorno dado pelas professoras, definindo que ele se referia ao banho indicam essa dinâmica da apropriação pelo bebê do sistema semiótico da linguagem verbal, como quem acessa um universo de significações mediado pelos signos e pelo outro (PINO, 2005).

A professora dá banho em Ana. Clara e Heitor agarram na perna dela e choram
porque também querem tomar banho. A professora dá o banho conversando
com Ana, mas também com Clara e Heitor. Fala que eles já tomarão banho, que
precisam esperar um pouquinho. Um deles para um pouco de chorar, depois
volta. E ambos continuam ali abraçados na perna da professora. (Caderno de campo, 22/05/16)

A professora tinha a perna abraçada pelas duas crianças que expressavam insatisfação ou possível ansiedade para o banho e sono que viria em seguida. Em nenhum momento pediu que Clara e Heitor deixassem de segurar a sua perna ou teve alguma atitude que demonstrasse impaciência com eles. Além disso, permanecia em contato com o bebê que banhava.

A manifestação afetiva, expressiva e corporal dos bebês, tal como sugere Wallon (2005), é respondida afetivamente pela professora também, pela modulação verbal. Ela se coloca disponível para aqueles que demandam a sua atenção por meio do choro, conversando com eles; bem como há uma ação atenta e cuidadosa com o bebê em quem está dando o banho.

Schmitt (2014) chama a atenção para os contornos da ação docente na creche, identificando como uma das principais marcas da professora de bebês a multiplicidade simultânea das relações. Atentar ao mesmo tempo para as singularidades e o coletivo, para diversas demandas simultâneas de atenção são elementos que caracterizam a docência na creche. Ou seja, o planejamento e a intencionalidade pedagógica deveriam envolver essas questões. Nestas situações 
descritas, o momento do banho pareceu peculiar neste sentido. Tratase de situação de atenção individual que permite olho no olho, diálogo com cada bebê, colocando o adulto numa situação responsiva particular, demandando planejamento que permita essa qualidade relacional.

No entanto, a cena provoca indagações: não seria importante planejar um momento do banho onde enquanto uns são banhados os outros possam estar envolvidos em outras atividades com outro professor? Ou mesmo, não seria interessante repensar a rotina de modo que todos os bebês não precisem tomar banho num mesmo horário?

De modo geral, a maneira das professoras procederem no antes, durante e depois do banho, como no toque cuidadoso, contudo firme, esperando o tempo do bebê de se acostumar com a temperatura da água, de ficar dentro da banheira, de se sentar, ao passar o shampoo, indicam uma relação que considera o outro com respeito ao que tange a singularidade. Podemos dizer que o toque e o olhar sinalizam uma escuta com o corpo todo; ou seja, disponibilidade para considerar o outro-bebê como parceiro ativo na interação.

Por vezes, a professora pedia a um bebê que se sentasse para ajudá-la a dar o banho sem que ele se machucasse. Também a fala mostrava a consideração pela criança como parceira de um diálogo.

O Eduardo parece não gostar de sentar na banheira para tomar o banho. A professora conversa com ele sem forçá-lo a se sentar. Pede a ele que se sente para ajudá-la a dar o banho melhor. Ele olha para ela, começa a se molhar e senta.

(...)

Marina chora com medo do ralo da banheira.

A professora conversa com ela e diz:

- "Marina, é só um ralo. Ele não vai te fazer mal nenhum. Ele está aqui para poder a água do banho sair da banheira".

Mostra a ela o ralo, explica para o que serve. Marina chora mais um pouco e depois para.

Naquele dia ela estava um pouco assustada. Já tinha chorado com medo de um pato inflável que estava na sala e as professoras tiraram o pato. Depois ela chorou porque não queria comer e foi para o colo da professora. As professoras a acolheram e conversaram com ela.

(Caderno de campo, 23/02/16)

Essas situações remetem-nos às ideias de Wallon. Para o autor, no primeiro ano de vida, o bebê humano experimenta uma imensa dependência de parceiros mais experientes para a sua sobrevivência e, como coloca Galvão (2005, p. 60), "sua primeira atividade eficaz é desencadear reações de ajuda para satisfazer suas necessidades". No 
entanto, de modo concomitante à dependência encontra-se a potência de estabelecer relações e constituir-se nelas. Ao mesmo tempo em que depende do outro, o bebê é capaz de estabelecer múltiplas e significativas relações que o afetam, assim como afetam quem com ele se relaciona. Os bebês presentes na cena descrita mostram a potência em estabelecer contato.

Outro momento a ser refletido em sua qualidade relacional e afetiva é o sono. Para Sharmahd (2013), dormir significa abandonar-se, de certa forma, desligar-se da realidade em torno, experimentar "outro mundo", instigando-nos a pensar como é a relação com o que circunda o bebê, tendo em vista que ele possa viver de modo seguro esta experiência.

Num outro prisma, Coutinho (2002), numa pesquisa com o objetivo de conhecer as crianças e as suas culturas nos momentos de educação e cuidado corporais, observou uma vivência intensa das dimensões infantis que demarcam a alteridade da infância em situações que pouco consideravam as crianças como ponto de partida em seu planejamento ou no olhar do adulto. A autora traz uma questão relevante: as necessidades humanas são importantes na proposição de situações cotidianas mais voltadas para o corpo? Em relação ao sono, pode-se perguntar: os momentos planejados para essa finalidade possuem como intuito somente "fazer dormir" ou envolvem outras ações das crianças que também se constituem neste contexto, como o toque, as conversas, o embalar-se mutuamente? Se estes momentos dos cuidados corporais ocupam tanto tempo, é importante pensar a qualidade deste tempo, a intencionalidade pedagógica, o envolvimento afetivo dos profissionais presentes.

$\mathrm{Na}$ experiência da instituição aqui focalizada, durante o sono do grupo de bebês, quando alguma criança acordava ou chorava, as professoras demonstravam estar atentas às suas necessidades emocionais. Mostravam uma disponibilidade afetiva que acolhe o outro, o escuta e dá espaço a ele por meio das suas ações. Dormir e acolher pareciam duas faces da mesma moeda. No entanto, não foi possível perceber a atenção para a qualidade interativa das crianças entre si nestes momentos de descanso; ou seja, a arrumação das crianças de forma mais individualizada e a priorização do contato com os adultos marcavam as cenas.

Clara tem o sono leve e acorda com pequenos barulhos na sala. Abre o olho, se mexe, ensaia um choro. Uma professora que está perto dela fala: -"xi, xi, xi, xi..." Como quem com a voz pretende niná-la à distância.

Uma professora faz algum barulho na sala mista. Clara acorda, senta e chora. E Isabela que dormia ao seu lado acorda também. Choram as duas. 
A professora deita entre as duas para fazê-las dormir novamente. Depois de uns 20 minutos Isabela volta a dormir, mas Clara levanta um pouco chorosa.

Uma terceira professora pega Clara no colo. Levando-a até a janela, conversa, mostras objetos.

Clara então aponta para os livros e a professora e Clara ficam um bom tempo lendo juntas lendo vários livros de literatura. Clara olha os bichos das imagens dos livros, aponta e repete seus nomes.

(Caderno de campo, 01/03/16)

O movimento das professoras com os bebês que acordam e choram durante o período do descanso evidencia uma dinâmica corporal e verbal atenta às necessidades emocionais deles, visto que para além de fazer dormir, as professoras estão atentas às demandas afetivas dos bebês. Aconchego e diálogo revelam disponibilidade e acolhimento. $\mathrm{O}$ momento do sono é momento relacional: os adultos deitam junto aos bebês no colchão, pegam no colo, leem para e com eles. Oferecem segurança e amparo, estabelecendo com os bebês uma relação de confiança na qual eles podem se expressar.

A partir da perspectiva walloniana, podemos dizer que o bebê é corpo; o desconforto, a insatisfação, a fome, a dor, dentre outras sensações aparecem por meio do gesto, do choro, da agitação, do grito; do mesmo modo, o bem-estar e a saciedade materializam-se no sorriso, na agitação alegre, na expressão de conforto. $\mathrm{Na}$ ausência da fala do bebê como linguagem para compartilhar essas sensações, o meio onde ele está inserido vai dando contornos às manifestações corporais emocionais; isto é, são os outros que presenciam e compartilham com o bebê os momentos expressivos que respondem corporalmente (com a fala e os gestos), dão sentidos, afetam e são afetados pelo bebê no contexto interativo. Neste contexto, vale perguntar sobre a possibilidade dos bebês como agentes do contato com os adultos, como quem mobiliza iniciativas de atenção compartilhada.

$\mathrm{O}$ adulto fala, sorri, muda a criança de posição, canta, conversa, como um diálogo baseado em componentes corporais e expressivos, mobilizado também pela iniciativa da criança, ou numa perspectiva automática, mecânica? A intencionalidade expressiva do bebê constituise nestas interações onde ele responde e é também respondido.

Neste caminho, a relação com o choro também é relevante como campo de observação. Durante a pesquisa, as professoras buscavam diálogo não-verbal e verbal, entendido na perspectiva da comunicação. O objetivo delas não nos parecia ser o de silenciar o choro, mas de acolher a criança, de confortá-la, cuidar e partilhar atenção. Como afirma Schmitt (2014, p. 72), o choro é considerado 
"algo vital, natural e importante para o equilíbrio das emoções e das funções corporais, tanto orgânicas quanto posturais. [...] Lidar e acolher o choro são saberes absolutamente imprescindíveis para o trabalho docente na creche".

Neste movimento, podemos dizer que as professoras desenvolvem ações de cuidado, em relação a elas mesmas e às crianças. Guimarães (2011) afirma que "cuidar e cuidado (...) dizem respeito à criação de práticas do adulto para com ele mesmo, que produzem uma esfera de atenção, escuta e disponibilidade na creche como um todo" (p. 49). Cuidar nesta perspectiva ética também contagia e reverbera na creche, de modo particular nos cuidados corporais, o que percebíamos no contexto observado nesta pesquisa.

Os momentos de cuidado corporal pareceram relevantes no caminho de dar fecundidade à humanização dos bebês e às possibilidades dialógicas e afetivas. Trocas de atenção, olho no olho, respostas aos movimentos expressivos constituem o desenvolvimento de cada um dos bebês e colocam-se como ações docentes intencionais centrais no cotidiano da creche.

\section{CONSIDERAC̣ÕES FINAIS}

No decorrer deste trabalho, buscamos apresentar aspectos da relação entre a experiência afetiva, o movimento dialógico e a docência na creche, especialmente nos momentos de cuidado corporal. Para tal, encontramos na Filosofia da Linguagem, de Mikhail Bakhtin, uma interlocução importante acerca da educação enquanto prática dialógica, que compreende a formação do eu no enlace com o outro e o diálogo como constituinte do sujeito e do mundo. Ainda encontramos na perspectiva histórico-cultural de Henry Wallon pistas para considerar a afetividade como propulsora de encontros e construção de significatividade na relação do bebê com o outro. Essas ideias alinham-se com as pesquisas mais recentes sobre o trabalho pedagógico com os bebês e crianças pequenas.

Nesta pesquisa, o desafio de conhecer e compreender como se expressam a afetividade e as manifestações dialógicas na creche foi enfrentado numa investigação de caráter etnográfico. A partir da observação e descrição densa de eventos de interação dos adultos com as crianças no berçário de uma creche pública universitária, foi possível identificar nos momentos de cuidado corporal, potência no desenvolvimento de afetividade e diálogo. A qualidade ritualística destes momentos provoca continuidade e ampliação de formas de contato. 
$\mathrm{Na}$ perspectiva afetiva, percebemos contágio emocional, imitação e oportunidades férteis para os adultos significarem com a palavra as ações dos bebês. Nos momentos de refeição, no banho e no sono entrelaçavam-se manifestações afetivas corporais e verbais, mobilizando diálogo, troca, cotejo de perspectivas e desenvolvimento das crianças.

No plano dialógico, os momentos de cuidado corporal pareceram fecundos para dar lugar às respostas dos adultos em relação às iniciativas das crianças, alargando com suas falas os possíveis sentidos dos movimentos gestuais e corporais dos bebês. Assim, a prática pedagógica contempla uma intencionalidade que abarca a organização de contextos, a atenção para a inciativa das crianças, a resposta a essas iniciativas, a multiplicidade simultânea das relações, uma escuta responsiva.

A experiência no campo de pesquisa nos permitiu analisar as interações entre professor e bebês na creche, tendo como norte as discussões teóricas do âmbito da Educação Infantil. Foi possível perceber como é delicado e exigente o trabalho afetivamente disponível e atento com os bebês na creche. O diálogo - que não é feito unicamente com palavras -, o corpo que comunica suas emoções de modos variados, as demandas da rotina, a relação que se alterna entre o individual e o coletivo configuram desafios postos para pensar o trabalho pedagógico com as crianças pequenas.

As aprendizagens vão acontecendo permeadas pelas relações dialógicas e afetivas, ainda que essas experiências não envolvam os modelos tradicionalmente pensados para a escola como ensinar de modo transmissivo, "dar" conhecimento ou instruir. Ao invés destes termos, talvez os verbos mais indicados para ação pedagógica com os pequenos sejam oferecer, trocar, dialogar (seja com o corpo ou com a fala verbal), propor, esperar, encorajar, garantir, observar, dentre tantos outros que exprimam uma intencionalidade educativa respeitosa e conhecedora das especificidades da pedagogia na primeira infância.

A partir do que propõe Tristão (2004), a experiência educativa com os bebês é marcada pela sutileza das ações cotidianas - muitas vezes não percebidas na rotina diária, seja no toque, no olhar, na fala, na entonação da voz, na espera atenta ao momento do outro, na postura, na presença não invasiva, no encorajamento a experimentar o mundo e a construir autoconfiança. Cabe-nos buscar caminhos de relação com as crianças que considerem a dimensão afetiva e dialógica no seu desenvolvimento e proporcionem uma experiência de educação institucionalizada que fomente a autonomia, a segurança, a criação e alegria de estar no mundo. 


\section{REFERÊNCIAS}

AMORIM M. O pesquisador e seu outro: Bakhtin nas Ciências Humanas. São Paulo: Musa Editora, 2001.

BAKHTIN, M. Estética da Criação Verbal. São Paulo: Martins Fontes, 2011.

BAKHTIN, M. (N.V. Volochínov). Marxismo e Filosofia da Linguagem. São Paulo: Hucitec, 2014.

BARBOSA, M. C. As especificidades da ação pedagógica com os bebês. 2010. Disponível em: $<$ http:/ / portal.mec.gov.br/index.php?option $=$ com_docman\&view $=$ downl oad\&alias $=6670$-as especificidadesdaacaopedagogica\&Itemid=30192 > . Acesso em: 20 nov. 2015.

CASTRO, J. S. de. A constituição da linguagem entre os e dos bebês no espaço coletivo da educação infantil. Texto apresentado no GT7 da 36a Reunião da ANPED, 2013.

CATARSI, E. \& FRESCHI, E. Le attività di cura nel nido d'infanzia. Parma/Itália, Edizioni Junior, 2013.

COUTINHO, Â. M. S.. Educação infantil: espaço de educação e cuidado. Trabalho apresentado no GT7 da 25ª Reunião Anual da ANPED, 2002 (mimeo).

COUTINHO, Â. M. S. A ação social dos bebês: um estudo etnográfico no contexto da creche. Tese de Doutorado. Instituto de Educação - Universidade do Minho - Minho, Portugal 2010.

DAUSTER, T. Um saber de fronteira: entre a antropologia e a educação. Texto Apresentado na 26a Reunião da Anped, 2003. (Mimeo.)

GALVÃO, I. Henri Walon: uma concepção dialética do desenvolvimento infantil. Petrópolis, RJ: Vozes, 2005.

GEERTZ, C. A interpretação das culturas. Rio de Janeiro: Guanabara, 1989.

GUIMARÃES D. As relações entre os bebês e os adultos na creche: o cuidado como ética. São Paulo: Cortez, 2011.

LESSA, J. O espaço alimentar e seu papel na socialização da infância: o caso de uma creche pública. Dissertação (Mestrado). Universidade Federal de Santa Catarina Centro de Ciência da Educação. Programa de Pós-Graduação em Educação. Florianópolis, 2011.

MARTINS FILHO, A. J. Educar na creche: uma prática construída com os bebês e para os bebês. Porto Alegre: Editora Mediações, 2016.

OLIVEIRA, R. C. de. O trabalho do antropólogo: olhar, ouvir e escrever. Revista de Antropologia. São Paulo v. 39 (1), 1986.

PINO, Angel. As marcas do humano. São Paulo: Cortez, 2005.

RAMOS, T. K. G. R. A criança em interação social no berçário da creche e suas interfaces com a organização do ambiente pedagógico. Tese (Doutorado em Educação). Universidade Federal de Pernambuco. Recife, 2010. 
ROCHA, E. C. \& BATISTA R. A constituição histórica da docência na Educação Infantil: um estudo a partir do contexto catarinense do início do século XX. Trabalho apresentado no GT7 da $37^{\mathrm{a}}$ Reunião anual da ANPED, 2015.

SALAZAR DE CASTRO, J. Constituição da linguagem entre os e dos bebês no espaço coletivo da educação infantil. Trabalho apresentado no GT7 da $36^{a}$ Reunião Nacional da ANPEd , 2013.

SARMENTO, M. J. (2011). O Estudo de Caso Etnográfico em Educação. In:ZAGO, N.; PINTO DE CARVALHO, M.; VILELA, R. A. T. (org.). Itinerários de Pesquisa Perspectivas Qualitativas em Sociologia da Educação. Rio de Janeiro: Lamparina, 2011.

SCHMITT, R. V. As relações sociais entre professoras, bebês e crianças pequenas: contornos da ação docente. Tese de Doutorado. Programa de Pós-Graduação em Educação - UFSC - Florianópolis, 2014.

SHARMAHD, N. A occhi chiusi: accompagnare il sonno dei bambini al nido. In: CATARSI E. \& FRESCHI E. Le attività di cura nel nido d'infanzia. Parma/Itália, Edizioni Junior, 2013.

TIRIBA, L. Educar e cuidar ou, simplesmente, educar? Buscando a teoria para compreender discursos e práticas. Trabalho apresentado no GT7 da 28ª Reunião Anual da ANPED, 2005.

TRISTÃO, F. C. Ser professora de bebês, uma profissão marcada pela sutileza. Faculdade de Educação: Universidade Federal de Santa Catarina. Florianópolis, 2004.

WALLON, H. A evolução psicológica da criança. Lisboa: Edições 70, 2005.

VELHO, G. O desafio da proximidade. In: VELHO, G.; KUSCHNIR, K. (org.). Pesquisas urbanas: desafios do trabalho antropológico. Rio de Janeiro: Jorge Zahar, 2003.

Submetido: $23 / 10 / 2017$

Aprovado: 25/03/2018

Contato:

Daniela Guimarães

Rua Constante Jardim 12 apto 203, Santa Teresa

Rio de Janeiro $\mid$ RJ |Brasil

CEP 20.240-230 